\title{
Prevention of type 2 diabetes in adults with impaired glucose tolerance: the European Diabetes Prevention RCT in Newcastle
} upon Tyne, UK

\author{
Linda Penn"1,2,3, Martin White*1,2,3, John Oldroyd4, Mark Walker ${ }^{3,5}$, K \\ George MM Alberti ${ }^{3,6}$ and John C Mathers ${ }^{2}$
}

\begin{abstract}
Address: ${ }^{1}$ Public Health Research Programme, Institute of Health and Society, Newcastle University, Newcastle upon Tyne, NE24HH, UK, ${ }^{2} \mathrm{Human}$ Nutrition Research Centre, Institute for Ageing and Health, Newcastle University, Newcastle upon Tyne, NE24HH, UK, ${ }^{3}$ Diabetes Research Group, Newcastle University, Newcastle upon Tyne, NE24HH, UK, ${ }^{4}$ Medicine, Nursing and Health Sciences, Monash University, Victoria 3800, Australia, ${ }^{5}$ Institute of Cellular Medicine, Newcastle University, Newcastle upon Tyne, NE24HH, UK and ${ }^{6}$ Department of Endocrinology and Metabolism, St Mary's Hospital and Imperial College, University of London, London, W2 1NY, UK

Email: Linda Penn - l.d.penn@ncl.ac.uk; Martin White* - martin.white@ncl.ac.uk; John Oldroyd - john.oldroyd@med.monash.edu.au; MarkWalker - Mark.Walker@newcastle.ac.uk; K George MM Alberti - george.alberti@ncl.ac.uk; John C Mathers - john.mathers@ncl.ac.uk

* Corresponding author
\end{abstract}

Published: 16 September 2009

BMC Public Health 2009, 9:342 doi: I0.1 I86/I47|-2458-9-342
Received: 21 May 2009

Accepted: 16 September 2009

This article is available from: http://www.biomedcentral.com/I47I-2458/9/342

(c) 2009 Penn et al; licensee BioMed Central Ltd.

This is an Open Access article distributed under the terms of the Creative Commons Attribution License (http://creativecommons.org/licenses/by/2.0), which permits unrestricted use, distribution, and reproduction in any medium, provided the original work is properly cited.

\begin{abstract}
Background: Diabetes prevalence is increasing. The Finnish Diabetes Prevention Study (DPS) showed a $58 \%$ reduction in Type 2 Diabetes (T2D) incidence in adults with impaired glucose tolerance (IGT). The European Diabetes Prevention Study (EDIPS) extends the DPS to different European populations, using the same study design. In the Newcastle arm of this study (EDIPSNewcastle), we tested the hypothesis that T2D can be prevented by lifestyle intervention and explored secondary outcomes in relation to diabetes incidence.
\end{abstract}

Methods: We recruited 102 participants (42 men and 60 women, mean age 57 years, mean BMI $34 \mathrm{kgm}^{-2}$ ) with IGT to EDIPS-Newcastle and randomised to Intervention and usual care Control groups. The intervention included individual motivational interviewing aimed at: weight reduction, increase in physical activity, fibre and carbohydrate intake and reduction of fat intake (secondary outcomes). The primary outcome was diagnosis of T2D.

Results: Mean duration of follow-up was 3.1 years. T2D was diagnosed in 16 participants $(I=5, C$ $=1 \mathrm{I})$. Absolute incidence of T2D was 32.7 per 1000 person-years in the Intervention-group and 67.I per 1000 person-years in the Control-group. The overall incidence of diabetes was reduced by $55 \%$ in the Intervention-group, compared with the Control-group: RR $0.45(95 \% \mathrm{Cl} 0.2$ to I.2).

Explanatory survival analysis of secondary outcomes showed that those who sustained beneficial changes for two or more years reduced their risk of developing T2D.

Conclusion: Our results are consistent with other diabetes prevention trials. This study was designed as part of a larger study and although the sample size limits statistical significance, the results contribute to the evidence that T2D can be prevented by lifestyle changes in adults with IGT. In explanatory analysis small sustained beneficial changes in weight, physical activity or dietary factors were associated with reduction in T2D incidence. 
Trial Registration: International Standard Randomised Controlled Trial Number registry (ISRCTN)

\author{
Registry number: ISRCTN I5670600 \\ http://www.controlled-trials.com/isrctn/search.html?srch=15670600\&sort=3\&dir=desc\&max $=10$
}

\section{Background}

The prevalence of type 2 diabetes (T2D) is increasing rapidly and there are causal associations with obesity, diet and physical inactivity[1]. In the UK almost $5 \%$ of people have T2D and treatment costs absorb a high proportion of the health care budget[2]. Type 2 diabetes affects both quality of life and mortality and is a growing public health challenge.

Type 2 diabetes is a progressive metabolic disease with impaired glucose tolerance (IGT) as an early stage in disease development [3]. Several large, well-designed trials with long-term follow-up, evaluating interventions to prevent the onset of diabetes in people with IGT have been published [4-8]. The Finnish Diabetes Prevention Study (DPS) showed a 58\% reduction in T2D incidence following lifestyle intervention in adults with IGT[8]. The European Diabetes Prevention Study (EDIPS) extends the DPS to different European populations, using a similar study design $[9,10]$. The other EDIPS centres, in addition to Finland and Newcastle, are in Maastricht, the Netherlands and Sardinia, Italy.

The EDIPS in Newcastle upon Tyne, UK (EDIPS-Newcastle) was designed to contribute to the evidence for diabetes prevention by lifestyle modification in people with IGT. In this paper, we describe the methods and report both pragmatic and explanatory analyses of EDIPS-Newcastle in relation to diabetes prevention.

\section{Methods}

\section{Ethics statement}

The Newcastle and North Tyneside NHS Research Ethics Committee approved the study protocol and all participants gave informed, written consent before the start of the study.

\section{Study design, randomisation and end points}

We conducted a Randomised Controlled Trial (RCT) with one Intervention and one Control arm. Participants were randomly allocated either to intensive behavioural interventions to promote dietary modification and increased physical activity or to a minimal intervention Control group. The planned maximum follow-up for any individual was five years.

Recruitment was by referral from primary care physicians who identified eligible people likely to be at risk of impaired glucose regulation (using the criteria: aged over 40 and overweight (BMI > $\left.25 \mathrm{kgm}^{-2}\right)$ ) from their primary care databases and invited them to participate.

Oral glucose tolerance tests (OGTT) were conducted in the Clinical Research Facility, Royal Victoria Infirmary Newcastle upon Tyne. Eligible participants (with IGT) were randomly allocated to the Intervention (I) or Control (C) group using randomisation lists, prepared independently by the EDIPS co-ordinating centre in Helsinki. Randomisation was stratified by sex and by two hour plasma glucose value (derived from the mean of two standard oral glucose tolerance tests (OGTTs) - stratum 1: 7.8 to $9.4 \mathrm{mmol} / \mathrm{l}$; stratum 2: 9.5 to $11.1 \mathrm{mmol} / \mathrm{l}$ ). Blinding of participants and intervention staff was not possible. Data collection staff were blinded to the extent that this was possible given participants' knowledge of their allocation.

\section{Outcomes}

1. Development of T2D, diagnosed on the basis of two OGTTs conducted with 1-12 weeks of each other, assessed annually from baseline, was the primary study end point.

2. Other end points were myocardial infarction or sudden cardiac death, intermittent claudication, stroke or death from other causes.

3. Secondary outcomes were changes in BMI $\left(\mathrm{kgm}^{-2}\right)$, intakes of carbohydrate and fat (as percentages of total energy intake) and dietary fibre (g), and participation in physical activity (minutes of moderate aerobic physical activity per day).

\section{Inclusion and exclusion criteria}

We included people aged over 40 years with BMI $>25$ $\mathrm{kgm}^{-2}$ and with established IGT defined as a mean 2-hour plasma glucose value $\geq 7.8 \mathrm{mmol} / \mathrm{l}$ and $<11.1 \mathrm{mmol} / \mathrm{l}$ from two consecutive standard OGTTs (glucose load $75 \mathrm{~g}$ ) conducted between one and 12 weeks apart (World Health Organisation 1999 classification)[11]. If the 2-h OGTT value was just over the diabetes threshold (11.1$11.5 \mathrm{mmol} / \mathrm{l})$ or under the IGT threshold $(7.3-7.7 \mathrm{mmol} /$ $1)$, a second OGTT was performed within 1-12 weeks. If the mean of the 2-h values from the two OGTTs was $\geq 7.8$ and $<11.1 \mathrm{mmol} / \mathrm{l}$ the individual was eligible for inclusion. A diabetic value in the second OGTT was an exclusion criterion, even if the mean value was in the IGT range. 
People with previous diagnosis of diabetes, or with chronic illness that would make participation in moderate physical activity impossible, or on a special diet for medical reasons were excluded.

\section{Measurements}

All participants received a clinical assessment prior to randomisation and annually thereafter, including an OGTT, anthropometric and blood biochemistry measurements. Additionally they were asked to complete a health status questionnaire (RAND-36),[12] the WHO cardiovascular questionnaire[13] and annual three-day (two week days and one weekend day) diet and physical activity diaries.

Assessments were conducted in the Clinical Research Facility, Royal Victoria Infirmary in Newcastle upon Tyne.

Body weight was measured to the nearest $0.1 \mathrm{~kg}$ in light indoor clothing using SECA 770 electronic scales (Alpha Model 770, SECA Limited, Birmingham, UK). Height was measured to the nearest half centimetre using a SECA 225 stadiometer (SECA Limited, Birmingham, UK). Waist circumference was measured to the nearest centimetre at the midpoint between the iliac crest and the lower rib margin. Percentage body fat was measured by bioelectrical impedance, using a BODYSTAT 1500 (BODYSTAT Ltd, Douglas, Isle of Man, UK).

Blood was collected from the antecubital vein with the participant in a sitting position using a needle to insert a cannula. If a tourniquet was used it was opened immediately after the needle had entered the vein. Glucose was measured in venous plasma, using a Yellow Springs glucose analyser (Yellow Springs Instrument co Inc, Ohio, USA.). Food portion sizes were validated by the study dietician using a photographic food atlas [14] and nutrient composition was analysed using Microdiet software (Downlee Systems, Salford, UK). The activity diary covered the whole 24 hour period on all three days. Participants were asked to record activity for each 30 minute period throughout the day starting from midnight (midnight to $00.30,00.30$ to $1.00,1.00$ to 1.30 etc.) using an integer scoring system based on MET scores. For example, lying down was scored 1 and brisk walking was scored 6 . A 24-hour activity score of 80 would be achieved by lying down for eight hours and sitting for the rest of the day. Thirty minutes of brisk walking would add four to a participant's score on any day.

\section{Interventions}

Behavioural interventions consisted of regular individual advice from a dietician and physiotherapist trained in motivational interviewing [15]. Intervention participants were also invited to some group sessions, notably 'cook and eat' events. They also received a regular quarterly newsletter. The newsletter contained: healthy eating recipes, nutritional information, suggestions for local walks, and exercise options. The dietary intervention provided advice and counselling to develop an individual plan for behaviour change, with the aim of achieving: $>50 \%$ total dietary energy intake from carbohydrate, reduced total and saturated fat intake with $<30 \%$ total dietary energy from fat, increased fibre intake, and weight loss to achieve BMI $<25 \mathrm{kgm}^{-2}[16]$. Analysis of participants' three day food diaries, collected quarterly, and regular weight and waist measurements were used to tailor individual dietary advice. The physical activity intervention was designed to encourage participation in increased physical activity equivalent to accumulating 30 minutes of moderate aerobic physical activity per day. Analysis of participants' three day activity diaries, collected quarterly, was used in motivational feedback and to tailor goals for increasing physical activity, which were negotiated at each visit.

Participants in the Intervention group were seen by the intervention team (dietician and physiotherapist) for approximately 30 minutes per session, immediately following randomisation and two weeks later, then monthly for the first three months and every three months thereafter up to five years. In addition to individual and group activities, participants received an information pack detailing facilities and opportunities for physical activity in Newcastle upon Tyne, a City Card (a discount scheme run by Newcastle Leisure Services offering up to $80 \%$ discount on access to physical activity facilities) and the opportunity to meet with a trainer at a local leisure centre and take part in an induction session. Information generated from earlier studies in Newcastle was used to tailor the intervention to the local conditions [17-19]

\section{Control condition}

Both Intervention and Control groups were offered standard health promotion advice including widely available contemporary written leaflets on healthy eating and physical activity. Control group participants were otherwise offered 'usual care' by their primary care physician.

\section{Sample size}

EDIPS-Newcastle was designed to contribute to the European study. We aimed for a sample size of 100 participants (50 in each arm), contributing to a planned total of 750 participants across Europe.

\section{Analysis}

The Statistical Package for Social Scientists (SPSS inc. version 15) was used for analyses. We used independent ttests to compare continuous variables and Chi-squared tests to compare categorical variables in the Intervention 
and Control groups at baseline. Pragmatic (intention-totreat) analysis of the primary endpoint was conducted using Kaplan-Meier survival analysis to determine the difference in relative risk of cumulative incidence of diabetes between the Intervention and Control groups.

For secondary outcomes we used independent t-tests to compare the Intervention and Control group means of continuous variables at baseline and in each year of the study.

For the explanatory analyses of secondary outcomes, we pooled the Intervention and Control groups and considered each secondary outcome measure in turn. For these outcomes we used a scoring system whereby any individual's beneficial change from their baseline value in an outcome measure was scored 1 for each year of beneficial change (cut off change values were 0.01 for beneficial increase or -0.01 for beneficial reduction) and all other values (no change or detrimental change) were scored 0. The scores for each participant were totalled across study years and the participants were divided into two groups (for each measure separately): a 'sustained change' group with a score of two or more, indicating beneficial change in the parameter for at least two years; and a 'no sustained change' group with a score less than 2 , indicating less than two years beneficial change, no change or detrimental change. These groups were then compared using KaplanMeier survival analysis for progression to T2D. We also used independent t-tests to compare the 'sustained change' and 'no sustained change' group means and the difference between the groups for each of the secondary outcomes at baseline and in each year of the study. Two years of sustained change was chosen as the criterion for explanatory analysis groups after consideration of other possibilities (e.g. one year or three years) and with reference to the findings of our qualitative study linked to this trial[20].

The baseline characteristics, weight, height, BMI, waist circumference, hip circumference, body fat \%, plasma glucose (fasting, 30 minute, 60 minute and 120 minute), plasma insulin (fasting, 30 minute and 120 minute), age, sex, socioeconomic status and working capacity of the 'sustained change' and 'no sustained change' groups for each secondary outcome were compared for equality with t-tests or Chi-squared tests as appropriate.

\section{Results}

\section{Recruitment}

We recruited 102 participants to the study and they were randomised in equal numbers to the Intervention and Control groups. Recruitment and trial progression are shown in Figures 1 and 2.

\section{Progression and trial profile}

In the first year 19 participants ( $\mathrm{I}=11, \mathrm{C}=8$ ) left the study. The mean age of those who left in the first year was 54.8(95\% CI: 49.3 to 60.4$)$ years compared with 57.2 years (95\% CI: 55.5 to 59.8 ) for those who stayed in the study.

\section{Comparison of Intervention and Control groups at baseline}

There was little difference in any of the anthropometric, clinical, social or demographic characteristics of the two groups measured at baseline (Tables 1 and 2). Participants were taking a range of drugs, including statins, beta blockers, anti-inflammatory medication and ACE inhibitors. There were no significant differences in medication between Intervention and Control groups.

\section{Main outcomes}

Mean duration of follow up was 3.11 years (range 0 to 5 ). T2D was diagnosed in a total of 16 participants $(\mathrm{I}=5, \mathrm{C}=$ 11). The absolute incidence of T2D was 32.7 (95\% CI: 10.7 to 74.6$)$ per 1000 person years of follow-up in the Intervention group and 67.1 (95\% CI: 34.2 to 117.5$)$ per 1000 person years of follow-up in the Control group. The relative risk of T2D in the Intervention group, compared with the Control group was 0.45 (95\% CI: 0.2 to 1.2 ). After year two of follow-up, there were no further incidences of T2D in the Intervention group. Thus, overall the cumulative incidence of diabetes was 55\% less in the Intervention group compared with the Control group. Kaplan-Maier Survival analysis for Intervention and Control groups is shown in Figure 3.

A post study power calculation showed that 51 per group provided $37 \%$ power to detect the difference found $(80 \%$ power would have required 149 per group, a number that will be exceeded in pooled analyses with other EDIPS centres).

If participants who left the trial and were later reported to have developed T2D by their physician were included in the analysis as having developed diabetes (rather than having left), then the number of cases of diabetes becomes $20(\mathrm{I}=7, \mathrm{C}=13)$ and the relative risk of diabetes incidence becomes 0.54 (95\% CI:0.2 to 1.2 ).

\section{Secondary outcomes}

There were no significant differences in mean values for secondary outcome measures between the Intervention and Control groups at baseline or at annual follow-up in any year. Analysis of difference from baseline value in these secondary outcome measures showed a significant difference between Intervention and Control groups in weight loss at year 1 follow-up only (mean weight change: 


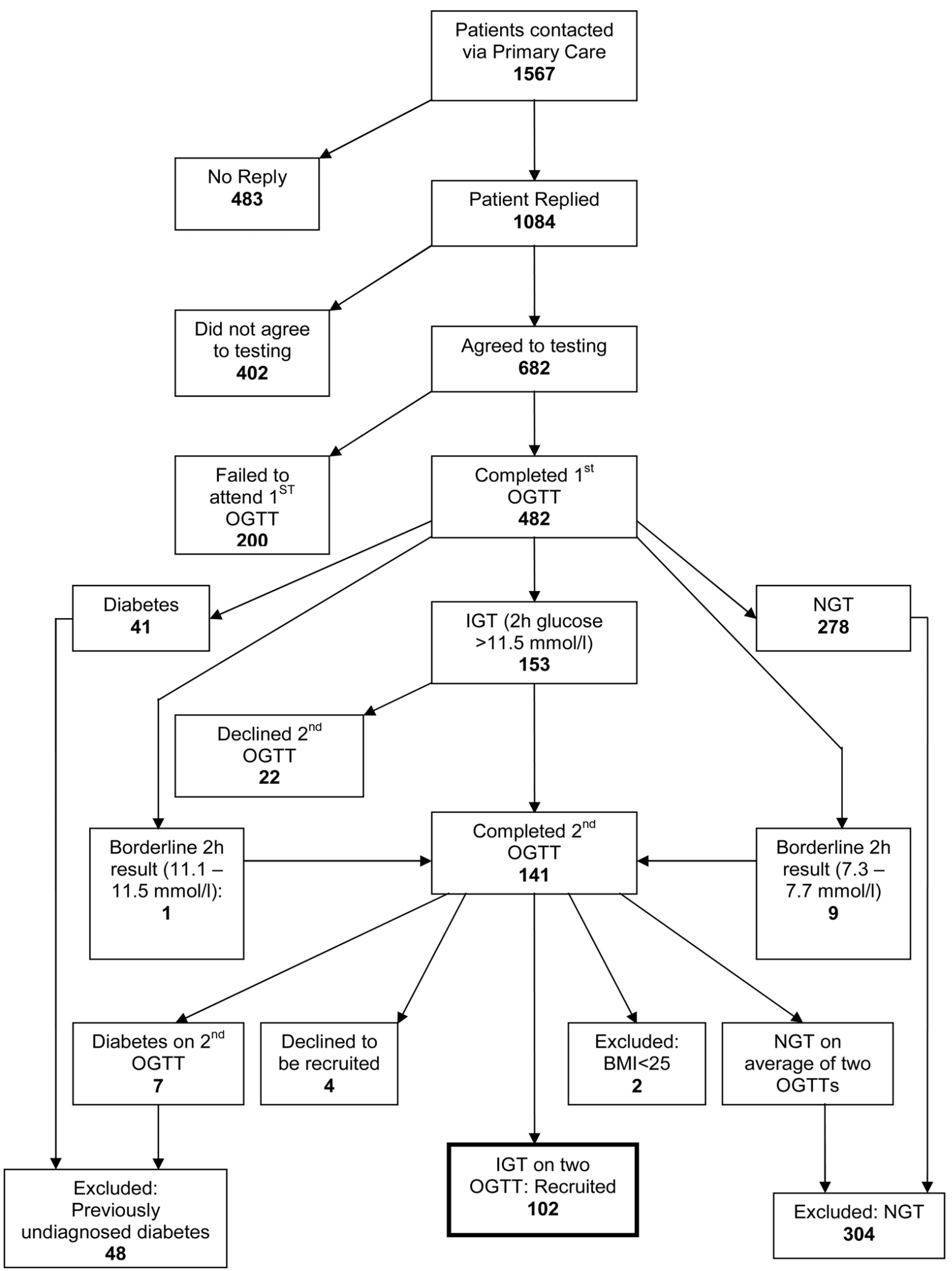

Figure I

Flow of participants during recruitment to EDIPS-Newcastle. 


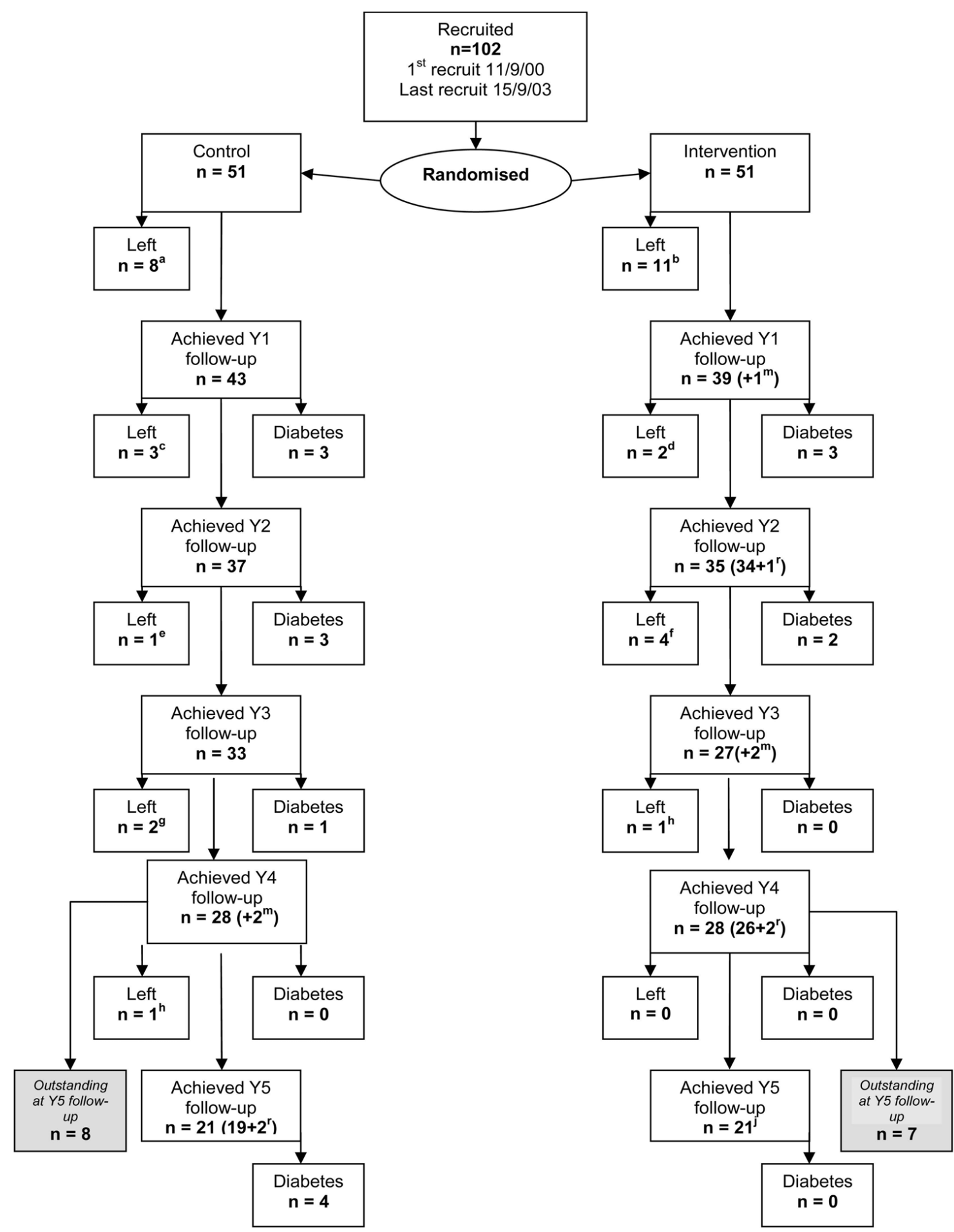

Figure 2

Flow of participants through EDIPS-Newcastle RCT. m participants who missed an annual review, but returned the following year (counted in for the survival analysis). ${ }^{r}$ participants returning after missing an annual review Reasons for leaving the trial: a lack of time $=4$, physician diagnosis $=I$, illness $=3$ ( I of these died of colon cancer a year later) $b$ lack of time $=5$, changed mind $=2$, physician diagnosis $=I$, not known $=2$, died $=I$ c not known=2, mother died $=I d$ not known=I, family bereavement $=I$ enot known=I flack of time $=I$, not known $=I$, illness $=I$, back surgery $=I \mathrm{~g}$ lack of time $=I$, illness $=\mathrm{I}$ lack of time $=\mathrm{I}$ lack of time $=\mid \mathrm{i} I=$ completed to year 5 and died later of lung cancer 
Table I: Baseline characteristics: mean (SD) for continuous variables by trial group.

\begin{tabular}{|c|c|c|}
\hline Measurement & Intervention $(n=5 I)$ & Control $(n=5 I)$ \\
\hline BMI $\left(\mathrm{kgm}^{-2}\right)$ & $34.1(5.5)$ & $33.5(4.6)$ \\
\hline Waist $(\mathrm{cm})$ & $104.6(11.3)$ & $104.3(9.2)$ \\
\hline $\mathrm{Hip}(\mathrm{cm})$ & $111.0(11.7)$ & II $0.3(9.0)$ \\
\hline Weight (kg) & $93.4(16.0)$ & $90.6(12.5)$ \\
\hline Height (cm) & $165.5(8.9)$ & $164.9(10.2)$ \\
\hline Body fat $\%$ & $40.2 *(9.4)$ & $40.1(9.9)$ \\
\hline \multicolumn{3}{|c|}{ Plasma glucose (mmol/l) } \\
\hline Fasting & $5.7(0.6)$ & $5.8(0.5)$ \\
\hline 30 minute & $9.9(1.3)$ & $9.8 *(0.9)$ \\
\hline 60 minute & $11.5(1.9)$ & $11.5 *(1.6)$ \\
\hline 120 minute & $8.7(1.1)$ & $8.9(1.3)$ \\
\hline \multicolumn{3}{|c|}{ Plasma insulin (mU/l) } \\
\hline Fasting & $16.9(12.4)$ & $17.3(7.4)$ \\
\hline 30 minute & $97.5(47.1)$ & $85.08(40.4)$ \\
\hline 120 minute & $118.0(58.0)$ & $122.18(55.3)$ \\
\hline
\end{tabular}

$*_{n}=49$

Intervention group $=-2.3 \mathrm{~kg}$, Control group $=0.01 \mathrm{~kg}$; mean difference -2.5 (95\% CI: -4.2 to 0.7$) \mathrm{kg}$, $\mathrm{p}=0.007)$. Only three participants achieved BMI $<25 \mathrm{kgm}^{-2}$.

Post-hoc analysis of reversion to normal glucose tolerance showed no difference between the intervention and the control groups either for reversion to normal glucose tolerance on at least one occasion $(\mathrm{I}=23, \mathrm{C}=22$ : $\mathrm{RR} 1.1$ $95 \% \mathrm{CI} 0.7$ to 1.6$)$, or for reversion to normal glucose tolerance on two consecutive occasions $(\mathrm{I}=17, \mathrm{C}=11$ : RR $1.595 \%$ CI 0.8 to 3.0 ).

\section{Explanatory analysis of secondary outcomes}

The results of the explanatory survival analyses are shown in Tables 3 and 4 and Figures 4 and 5.

There was no significant difference at baseline between the 'sustained change' and 'no sustained change' groups defined by any of the secondary outcomes for the characteristics compared.
Explanatory survival analysis of secondary outcome measures showed that, irrespective of randomisation allocation, groups of individuals who sustained beneficial direction of change in secondary outcomes for two or more years reduced significantly their risk of developing T2D compared with others in the study. Kaplan-Meier Log Rank, Chi-Square results: weight 16.6 ( $\mathrm{p}<0.001)$, physical activity $12.0(\mathrm{p}=0.001)$, percentage carbohydrate intake $7.4(\mathrm{p}=0.007)$, percentage fat intake $11.5(\mathrm{p}=$ $0.001)$, or total fibre intake $4.2(\mathrm{p}=0.041)$ (Figure 4$)$.

There were almost equal contributions from the intervention and control allocations to each 'sustained change' group of individuals (Table 3 )

The mean values for secondary outcomes were significantly different at baseline for 'sustained beneficial change' and 'no sustained beneficial change' groups in each of the secondary outcome measures except body weight. In each case the 'sustained change' group had a

Table 2: Baseline characteristics: number (\%) by trial group for demographic variables.

\begin{tabular}{|c|c|c|}
\hline & Intervention $(n=5 I)$ & Control $(n=5 I)$ \\
\hline Age [mean (range)] & $56.8(40-72)$ & $57.4(38-74)$ \\
\hline \multicolumn{3}{|l|}{ Sex } \\
\hline Male & $2 I(4 I .2)$ & $20(39.2)$ \\
\hline Female & $30(58.8)$ & $31(60.8)$ \\
\hline \multicolumn{3}{|c|}{ Current working capacity } \\
\hline Retired & $24(47.1)$ & $23(54.8)$ \\
\hline Full working capacity & $18(35.3)$ & $17(40.5)$ \\
\hline Unable to work & $6(11.8)$ & 0 \\
\hline Data unavailable & $3(5.9)$ & $2(4.8)$ \\
\hline \multicolumn{3}{|c|}{ Socio-economic status by type of work } \\
\hline Manual & $23(45.1)$ & $26(51.0)$ \\
\hline Non-manual & $19(37.3)$ & $19(37.3)$ \\
\hline Data unavailable & $9(17.6)$ & $6(11.8)$ \\
\hline
\end{tabular}




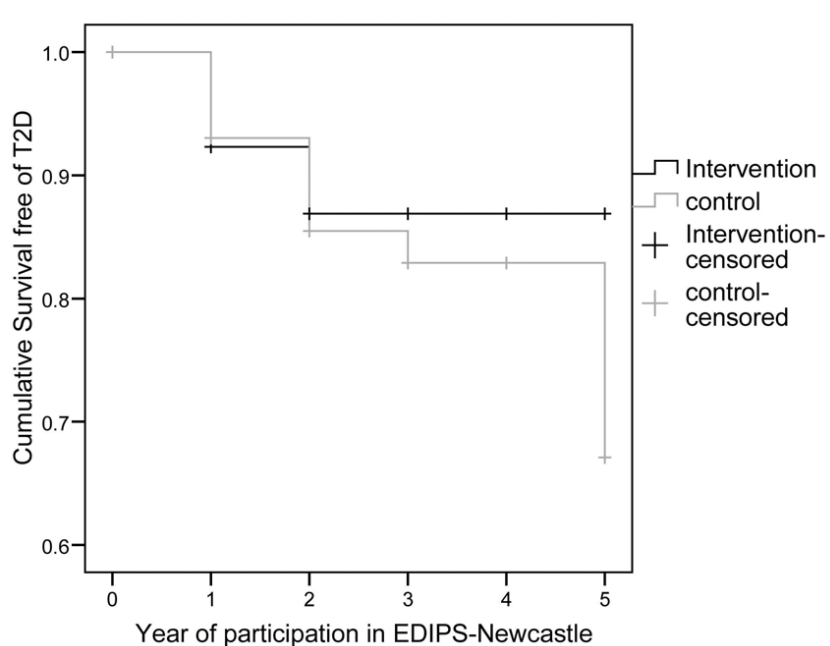

Figure 3

Progression to type 2 diabetes by trial group.

significantly less beneficial baseline value (Table 4). The sustained change group had significantly more beneficial values for percentage energy intake from fat from year 2 onwards and for fibre intake from year 1 onwards. The distribution of change, based on mean annual values, in the sustained change and no sustained change groups for each secondary outcome measure are shown in Figure 5 and Table 5.

\section{Discussion}

\section{Summary of main findings}

The results of the EDIPS-Newcastle suggest that progression to T2D can be prevented or delayed by interventions designed to change the lifestyles of participants with IGT. The overall incidence of diabetes was reduced by $55 \%$ in the Intervention group compared with the Control group, a magnitude of effect similar to that seen in the other main diabetes prevention trials [4-8]. However this study was designed as part of a larger study and was not powered for statistical significance.

Explanatory analysis highlights the efficacy of weight loss and of maintaining beneficial changes in diet and physical activity. The baseline differences in diet and physical activity measures suggest that those with the greatest capacity for beneficial change at baseline (because they were furthest from the healthy targets) were most able to sustain and to benefit from the changes made. The annual changes (means and distributions) in the groups that did and did not sustain beneficial change, demonstrate that small amounts of sustained change are effective in reducing risk.

\section{Strengths and limitations}

Our study built on the highly successful Finnish DPS, replicating its methods closely. Participants were recruited following two consecutive OGTTs taken between one and 12 weeks apart, providing strong evidence of IGT at baseline. The interventions were adapted for the UK cultural context, but we retained the same intervention targets for participants. A major strength was the length of follow-up (mean 3.1 years), equivalent to that achieved in the other main diabetes prevention trials [4-8].

As with any pragmatic trial, there were some limitations. EDIPS-Newcastle was planned as part of a larger study and was not powered to measure significant changes in incidence of T2D or secondary outcomes. Nevertheless, the results accord with previous trials and add to the existing evidence that progression to T2D can be prevented or delayed by lifestyle changes. Data will be pooled with those from other EDIPS collaborating centres for substantive analyses. Recruitment took longer than expected (18 months instead of 6 months), which meant that, despite an extension to the study period, we were unable to follow-up 15 cases at five years. Some of the problems in recruiting and maintaining the study sample are highlighted in Figures 1 and 2. Of the 141 people who received a second OGTT, 26 (18\%) were found to have reverted to NGT, more people than anticipated left the study early, especially in the first year for various reasons, and some participants failed to complete the baseline data collection.

In the explanatory analyses, we compared individual change in secondary outcomes with each participant's own baseline data. This had the advantages both of measuring the direction of individual change, which we classified as beneficial or not irrespective of whether the participant had achieved the intervention target (e.g. $>50 \%$ energy intake from carbohydrate), and taking account of individual variations in reporting (e.g. of dietary intake).

\section{Meaning and implications of the findings}

Our findings for the primary outcome concur well with previous trials and indicate $>50 \%$ reduction in risk of development of T2D is achievable in those with IGT when randomised to a lifestyle intervention [4-8]. In addition the results presented here, together with an associated qualitative study, [20] led us to investigate the effects of sustained beneficial behavioural change among some members of the Control group (in addition to participants in the Intervention group) and to determine the importance of maintaining change in the prevention of T2D. The explanatory analysis demonstrated the efficacy 
Table 3: Relationship between sustained change* in secondary outcomes and progression to T2D by trial group.

\begin{tabular}{|c|c|c|c|c|}
\hline & $\begin{array}{c}\text { Number in intervention } \\
\text { group (\%) }\end{array}$ & $\begin{array}{l}\text { Number in control } \\
\text { group (\%) }\end{array}$ & Total number (\%) & $\begin{array}{l}\text { Number of cases of T2D } \\
\text { over five years follow-up }\end{array}$ \\
\hline \multicolumn{5}{|l|}{ Body weight } \\
\hline Sustained beneficial change & $23(45)$ & $24(47)$ & $47(46)$ & 3 \\
\hline $\begin{array}{l}\text { No sustained beneficial } \\
\text { change }\end{array}$ & $28(55)$ & $27(53)$ & $55(54)$ & 13 \\
\hline \multicolumn{5}{|l|}{ Physical activity score } \\
\hline Sustained beneficial change & $18(35)$ & $19(37)$ & $37(36)$ & 2 \\
\hline $\begin{array}{l}\text { No sustained beneficial } \\
\text { change }\end{array}$ & $33(65)$ & $32(63)$ & $65(64)$ & 14 \\
\hline \multicolumn{5}{|l|}{ Intake of dietary fibre } \\
\hline Sustained beneficial change & $15(29)$ & $15(29)$ & $30(29)$ & 3 \\
\hline $\begin{array}{l}\text { No sustained beneficial } \\
\text { change }\end{array}$ & $36(7 I)$ & $36(7 I)$ & $72(71)$ & 13 \\
\hline \multicolumn{5}{|l|}{$\%$ energy intake from fat } \\
\hline Sustained beneficial change & $2 I(4 I)$ & $2 I(4 I)$ & $42(4 I)$ & 3 \\
\hline $\begin{array}{l}\text { No sustained beneficial } \\
\text { change }\end{array}$ & $30(59)$ & $30(59)$ & $60(59)$ & 13 \\
\hline \multicolumn{5}{|l|}{$\begin{array}{l}\% \text { energy intake from } \\
\text { carbohydrate }\end{array}$} \\
\hline Sustained beneficial change & $15(29)$ & $16(31)$ & $31(30)$ & 2 \\
\hline $\begin{array}{l}\text { No sustained beneficial } \\
\text { change }\end{array}$ & $36(7 I)$ & $35(69)$ & $71(70)$ & 14 \\
\hline
\end{tabular}

* Sustained beneficial change in secondary outcome measures was defined as: a beneficial change ( $>0.01$ units) maintained for two or more years (i.e. weight loss, reduction in \% energy intake from fat, increase in \% intake from carbohydrate, increase in intake of dietary fibre and increase in physical activity score).

of sustained lifestyle changes, where these were measured as individual beneficial change.

Whilst the control treatment was 'minimal intervention', it involved an annual clinical review and annual food intake and physical activity diaries. It has been recognised that a diagnosis of IGT, together with annual clinical reviews, constitute rather more than 'usual care'[21]. The motivational effect of monitoring needs to be assessed separately and considered in future pragmatic trials.

The problem of identifying persistent IGT for trial recruitment has been partly addressed since we commenced this trial by the development of prospective diabetes risk scores, such as FINDRISC [22]. Risk scores could also reduce the potential for selection bias when participants are recruited through primary care. Large trials, where the participants have been recruited on the basis of risk scores, are underway [23]. However risk scores do not diagnose T2D nor monitor progression, so the OGTT is likely to remain the diagnostic test of choice in future trials.

Different people require different motivational input to achieve behavioural change: for some, risk identification at baseline is decisive; others need continual support to change behaviour. In the Intervention group, engagement with the intervention varied from those participants who remained in the trial but returned only for the clinical reviews and those who attended all opportunities. In addition we were aware that some Control group participants sought help from elsewhere (e.g. weight loss groups). Future research should identify sub-groups with different levels of motivation for targeting with more or less intensive interventions.

Compared with the Finnish DPS, EDIPS-Newcastle had a larger proportion of participants who left the trial in the first year. In Finland much primary health care, including health promotion, is delivered via occupational health. This is not the case in the UK [24]. Some of our participants took a day from their employment annual leave allowance to attend their clinical review. Finding ways of improving the accessibility of intervention opportunities is an important area for further research.

Future pragmatic trials of the efficacy of lifestyle intervention in T2D prevention should address: achieving higher levels of recruitment; acceptable, ethical and efficient data collection tools; and acceptable, safe and efficient monitoring schemes to evaluate trial progression. This may 
Table 4: Mean (SD) values of secondary outcomes: comparison of sustained beneficial change* and no sustained beneficial change groups in each study year.

\begin{tabular}{|c|c|c|c|c|c|c|c|}
\hline \multirow[t]{2}{*}{ Outcome } & \multirow[t]{2}{*}{ Time } & \multicolumn{3}{|c|}{ Sustained beneficial change } & \multirow{2}{*}{$\begin{array}{c}\text { No sustained beneficial } \\
\text { change } \\
\text { Mean (SD) }\end{array}$} & \multirow{2}{*}{$\begin{array}{c}\text { Difference } \\
\text { Mean }(95 \% \mathrm{Cl})\end{array}$} & \multirow[t]{2}{*}{ p-value } \\
\hline & & $\mathbf{n}$ & Mean (SD) & $\mathbf{n}$ & & & \\
\hline \multicolumn{8}{|c|}{ Weight (Kg) } \\
\hline & Year 0 & 47 & $91.4(12.8)$ & 55 & $92.6(15.6)$ & $-1.2(-6.9,4.5)$ & 0.68 \\
\hline & Year I & 47 & $88.4(14.7)$ & 35 & $93.0(13.8)$ & $-4.6(-10.8,1.6)$ & 0.15 \\
\hline & Year 2 & 47 & $87.0(13.7)$ & 25 & $93.5(17.0)$ & $-6.5(-13.8,0.9)$ & 0.08 \\
\hline & Year 3 & 43 & $86.7(13.4)$ & 17 & $87.4(9.2)$ & $-0.7(-7.8,6.4)$ & 0.84 \\
\hline & Year 4 & 43 & $87.9(13.7)$ & 13 & $88.0(10.1)$ & $-0.1(-8.3,8.2)$ & 0.99 \\
\hline & Year 5 & 32 & $88.4(14.2)$ & 10 & $85.1(11.7)$ & $3.3(-6.8,13.3)$ & 0.52 \\
\hline \multicolumn{8}{|c|}{ Activity(score/day) } \\
\hline & Year 0 & 37 & $93.6(8.3)$ & 49 & 103.1 (16.7) & $-9.5(-15.4,-3.5)$ & 0.002 \\
\hline & Year I & 33 & $101.0(12.8)$ & 26 & $100.9(14.0)$ & $0.1(-6.9,7.07)$ & 0.99 \\
\hline & Year 2 & 31 & $102.5(12.4)$ & 18 & $96.6(14.1)$ & $6.0(-1.8,13.8)$ & 0.13 \\
\hline & Year 3 & 33 & $106.4(17.0)$ & 18 & $100.6(11.2)$ & $5.8(-3.1,14.7)$ & 0.20 \\
\hline & Year 4 & 34 & $105.3(11.6)$ & 13 & $97.9(12.6)$ & $7.5(-0.3,15.2)$ & 0.06 \\
\hline & Year 5 & 22 & $103.7(15.5)$ & 10 & $103.2(11.5)$ & $0.4(-10.8, \mid 1.7)$ & 0.94 \\
\hline \multicolumn{8}{|c|}{ Fibre (g/day) } \\
\hline & Year 0 & 30 & $17.6(6.1)$ & 54 & $20.5(6.5)$ & $-2.9(-5.8,-0.0)$ & 0.050 \\
\hline & Year I & 29 & $22.4(10.2)$ & 37 & $16.2(6.3)$ & $6.2(2.2,10.3)$ & 0.003 \\
\hline & Year 2 & 27 & $24.4(10.0)$ & 32 & $17.8(6.8)$ & $6.6(2.2,11.0)$ & 0.004 \\
\hline & Year 3 & 27 & $21.2(8.1)$ & 26 & I5.7 (5.3) & $5.5(1.7,9.3)$ & 0.005 \\
\hline & Year 4 & 24 & $21.5(7.9)$ & 22 & $16.7(7.4)$ & $4.7(0.2,9.3)$ & 0.043 \\
\hline & Year 5 & 20 & $20.6(8.2)$ & 13 & I5.I (4.9) & $5.4(0.3,10.6)$ & 0.039 \\
\hline \multicolumn{8}{|c|}{ Fat (\% energy) } \\
\hline & Year 0 & 42 & $37(07)$ & 51 & 31 (09) & $6.2(2.6,9.7)$ & 0.001 \\
\hline & Year I & 39 & $31(10)$ & 27 & $34(06)$ & $-2.2(6.5,2.1)$ & 0.306 \\
\hline & Year 2 & 37 & $31(06)$ & 22 & $35(06)$ & $-4.4(7.8,-1.0)$ & 0.011 \\
\hline & Year 3 & $4 I$ & $29(07)$ & 12 & $36(07)$ & $-6.2(-1.1,-1.7)$ & 0.007 \\
\hline & Year 4 & 36 & $29(06)$ & 10 & $35(06)$ & $-5.2(-9.5,-0.9)$ & 0.02 \\
\hline & Year 5 & 24 & $30(07)$ & 9 & $38(05)$ & $-8.3(-13.5,-3.1)$ & 0.003 \\
\hline \multicolumn{8}{|c|}{ Carbohydrate (\% energy) } \\
\hline & Year 0 & 31 & $44(07)$ & 52 & $49(08)$ & $-4.5(-8.1,1.0)$ & 0.013 \\
\hline & Year I & 28 & $48(11)$ & 38 & $48(10)$ & $-0.3(-5.4,4.6)$ & 0.89 \\
\hline & Year 2 & 26 & $50(07)$ & 33 & $46(10)$ & $3.3(-1.2,7.9)$ & 0.15 \\
\hline & Year 3 & 31 & $52(08)$ & 22 & $44(I I)$ & $8.4(3.1,13.7)$ & 0.002 \\
\hline & Year 4 & 28 & $5 I(10)$ & 18 & $47(08)$ & $3.5(-2.1,9.1)$ & 0.22 \\
\hline & Year 5 & 21 & $48(09)$ & 12 & $47(07)$ & $1.0(-5.2,7.2)$ & 0.74 \\
\hline
\end{tabular}

* Sustained beneficial change in secondary outcome measures was defined as: a beneficial change $(>0.01$ units) maintained for two or more years (i.e. weight loss, reduction in \% energy intake from fat, increase in \% intake from carbohydrate, increase in intake of dietary fibre and increase in physical activity score).

involve investigating more convenient times and locations for intervention delivery, including workplaces. Refining the physical activity and dietary advice within T2D prevention interventions to maximise initiation, magnitude and maintenance of change remains a continuing challenge and should be the subject of further investigation.

Diabetes prevention policies and management programmes are currently being implemented in some European countries, notably in Finland and Germany, and European guidelines for the primary prevention of T2D are being developed $[25,26]$
EDIPS-Newcastle was planned as part of a larger study. Subsequent analysis of data from the combined European study centres will further illuminate diabetes prevention.

\section{Conclusion}

In conclusion: the results of the Newcastle arm of the European Diabetes Prevention Study are consistent with those of other diabetes prevention trials. This study was designed as part of a larger study and although the sample size limits statistical significance, the results contribute to the evidence that T2D can be prevented by lifestyle changes in adults with IGT. In explanatory analysis we showed that small sustained beneficial changes in second- 


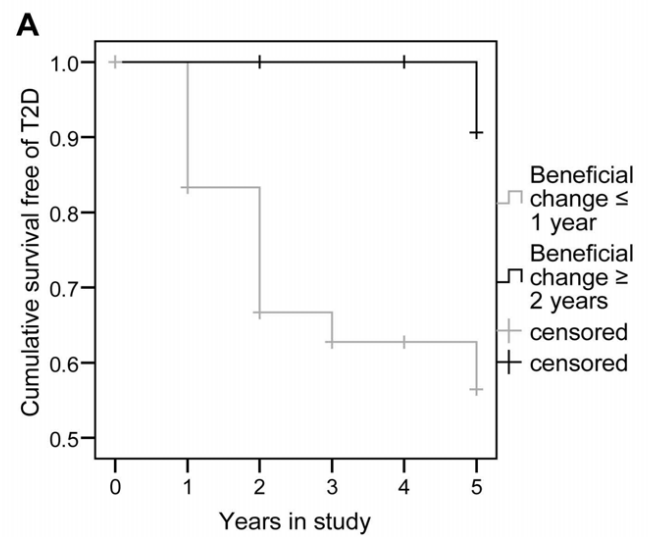

Test of equality of survival distributions:

Log Rank (Mantel-Cox) Chi-squared $16.62 p<0.001$

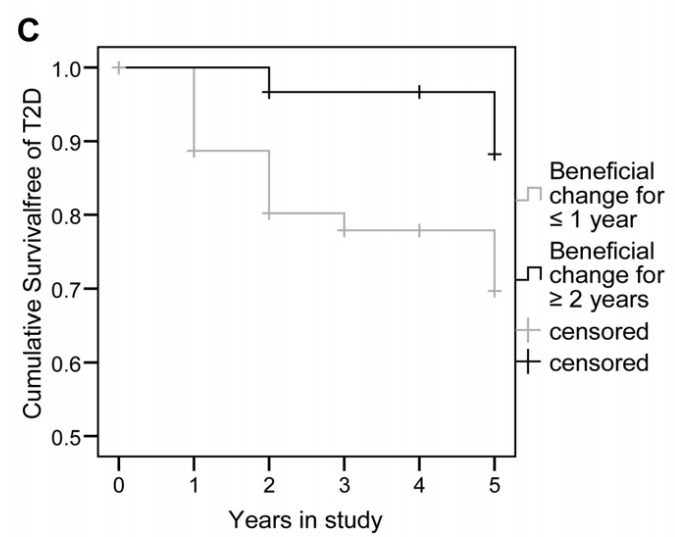

Test of equality of survival distributions:

Log Rank (Mantel-Cox) Chi-squared 4.20 p $=0.041$

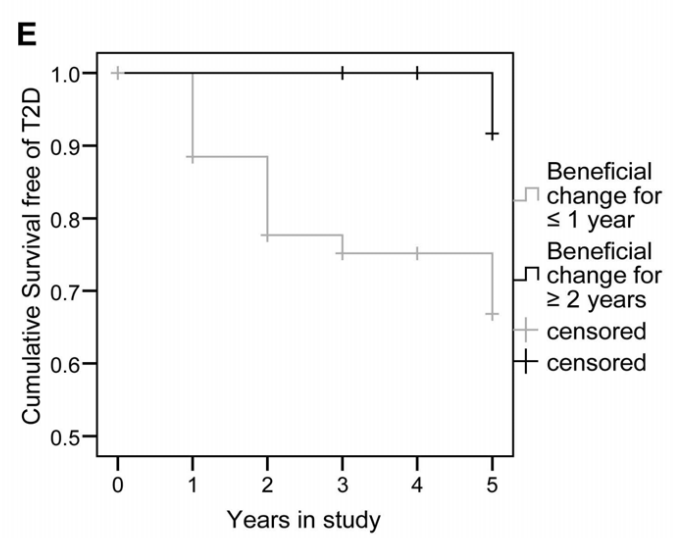

Test of equality of survival distributions:

Log Rank (Mantel-Cox) Chi-squared 7.38 p $=0.007$

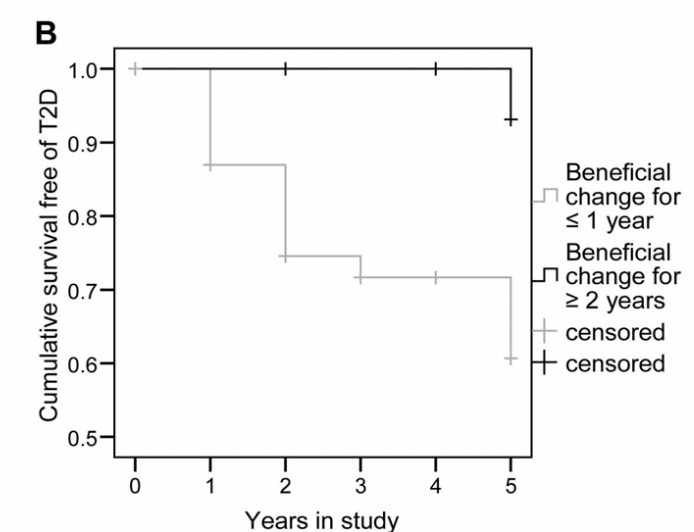

Test of equality of survival distributions:

Log Rank (Mantel-Cox) Chi-squared 12.03 p=0.001

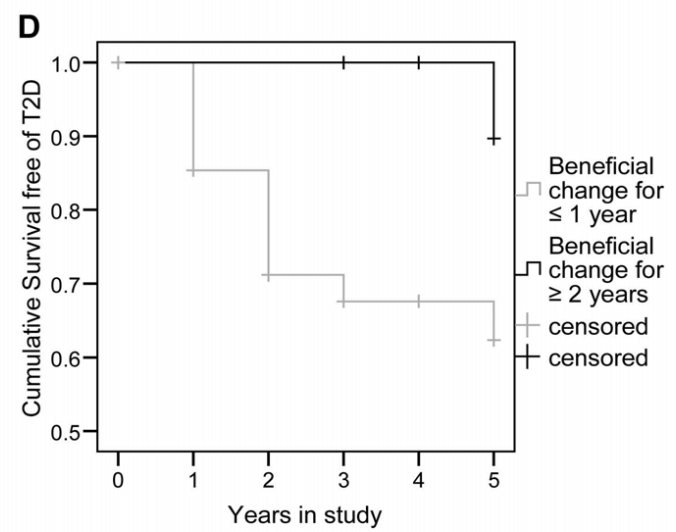

Test of equality of survival distributions:

Log Rank (Mantel-Cox) Chi-squared $11.46 \mathrm{p}=0.001$

\section{A Weight Loss \\ B Physical activity increase}

C Fibre increase

D Fat decrease

(\% dietary energy)

\section{E Carbohydrate increase}

(\% dietary energy)

Figure 4

Relationship between changes in secondary outcomes and progression to T2D in trial participants (trial groups pooled). This figure shows the results of survival analysis based on beneficial change in secondary outcome measures maintained for two or more years. Intervention and control group data was pooled for this analysis. 
Weight change

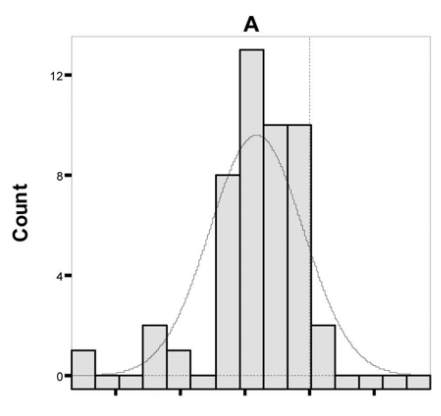

B

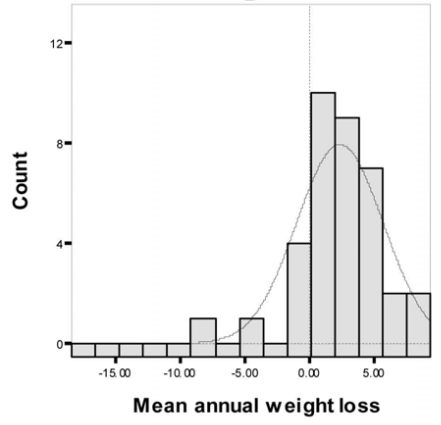

Fat change

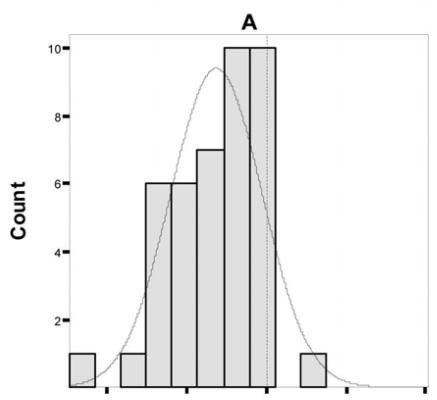

B

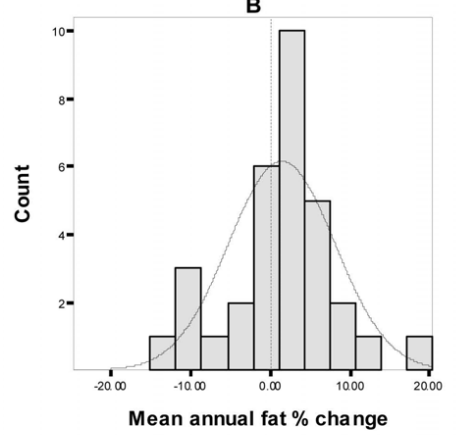

Activity change

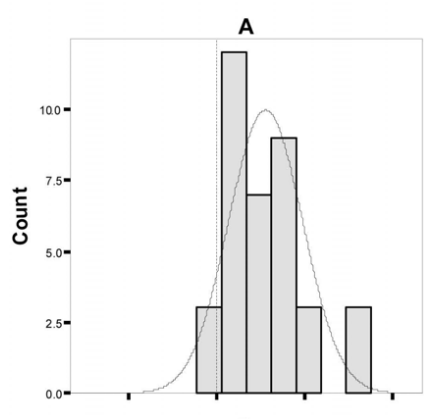

B

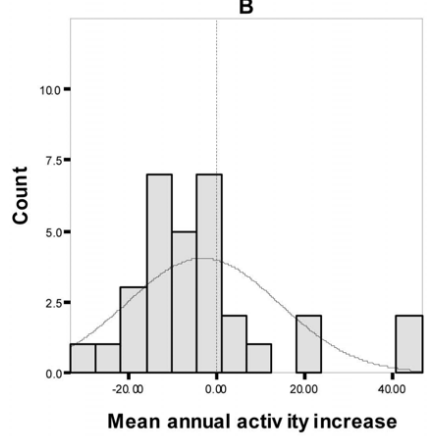

Carbohydrate change

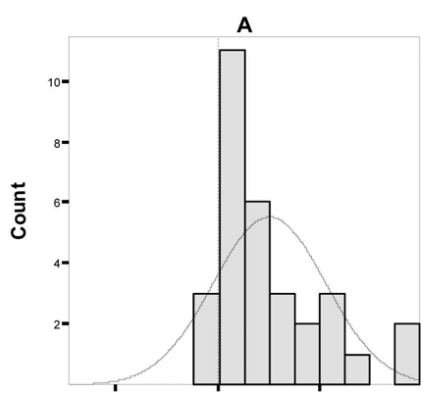

B

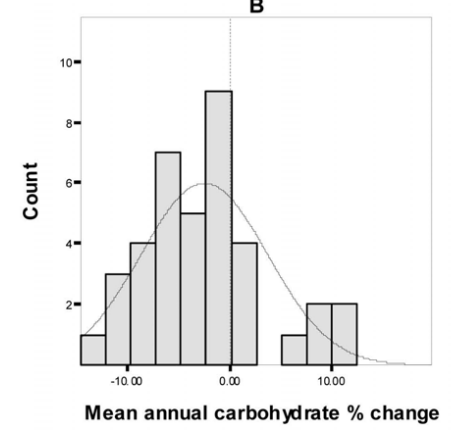

Fibre change
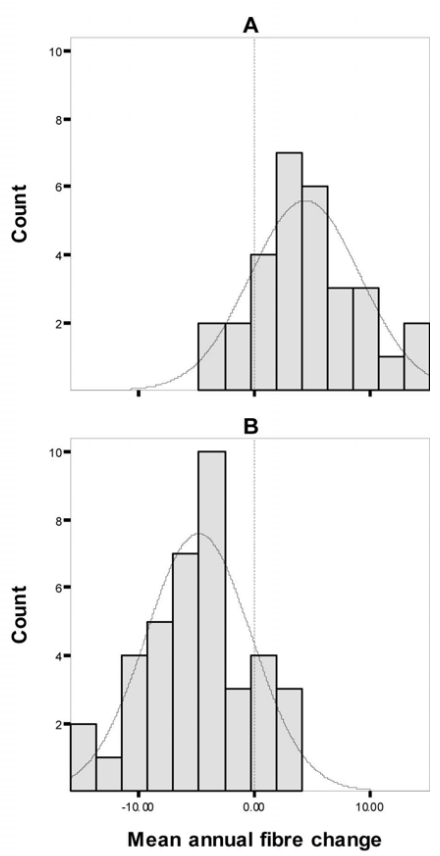

\section{Figure 5}

Mean annual changes in secondary outcome measures by sustained beneficial change $(A)$ and no sustained beneficial change (B) groups. This figure shows the range and distribution of change in secondary outcome measures in the two groups defined by A: 'beneficial direction of change in an outcome measure sustained for two or more years' and B: no beneficial direction of change in the outcome measure. Intervention and control group data was pooled for this analysis. 
Table 5: Mean (SD) of all years' annual change in secondary outcome measures: comparisonbetween sustained beneficial change* and no sustained beneficial change groups.

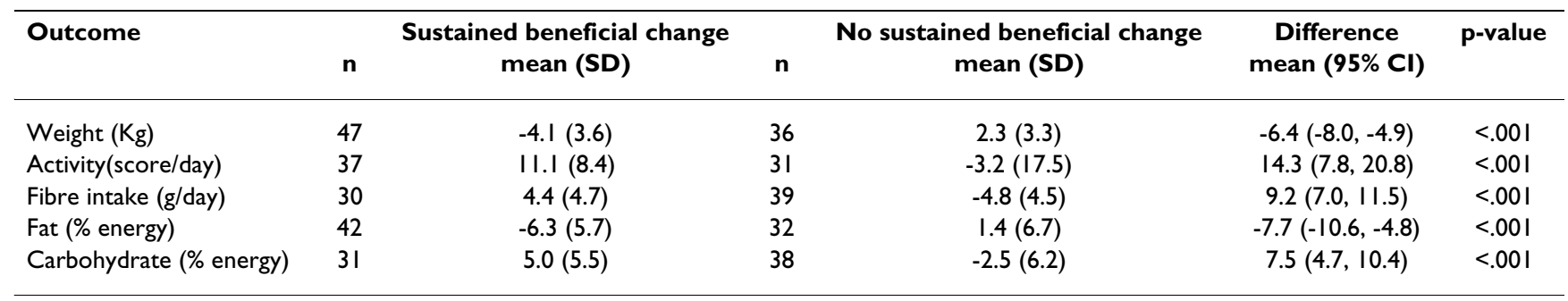

* Sustained beneficial change in secondary outcome measures was defined as: a beneficial change ( $>0.01$ units) maintained for two or more years (i.e. weight loss, reduction in \% energy intake from fat, increase in \% intake from carbohydrate, increase in intake of dietary fibre and increase in physical activity score).

ary outcome measures: weight loss, increase in physical activity, reduction in dietary energy intake, reduction in percentage fat intake and increase in percentage fibre intake, were associated with reduction in T2D incidence.

\section{Competing interests}

The authors declare that they have no competing interests.

\section{Authors' contributions}

MWh, JO, JCM and KGMMA designed the study, based on the Finnish DPS protocol, and MWh, JCM and KGMMA secured funding. MWa provided clinical advice. JO managed the fieldwork in year 1. LP managed the fieldwork from year 2, collated and analysed the data and, with MWh, drafted this paper. All authors commented on the manuscript and approved the final draft prior to publication. All authors are guarantors for this work.

\section{Acknowledgements}

We thank our participants and the following staff who helped with the study: Dr Peter Stephenson who provided medical supervision; Una Tohil who managed the project fieldwork during the first year; Michelle Short, Amelia Lake, and Karen Brown, dieticians who provided dietary intervention advice; Dave Purdy, Karen Imrie, Mark Blenkinsop, Nicola Watt and Elaine Nyman, physiotherapists who provided the physical activity intervention advice; Dorothy Carman and Judith Coulson who were the project nursing staff supporting the clinical measurements; Ruth Wood who designed our databases; Tom Chadwick who provided statistical advice; Terry Lisle, Laura Stokoe and Beth Edgar who provided secretarial support to the project.

The study was funded by the Wellcome Trust (Grant No. 057/46/Z/99/Z), from I ${ }^{\text {st } J a n u a r y ~} 2000$ to 3 Ist $^{\text {st }}$ December 2007

\section{References}

I. International Diabetes Federation: Diabetes Atlas 3rd edition. Brussels: International Diabetes Federation; 2006.

2. Roberts S: Improving Diabetes Services, the National Service Framework for Diabetes two years on. Edited by Health Do. London: TSO; 2005.

3. Saad MF, Knowler WC, Pettit DJ, Nelson RG, MA C, et al.: A two step model for the development of non-insulin dependent diabetes mellitus. American Journal of Medicine 1991, 90:229-235.

4. Gillies CL, Abrams KR, Lambert PC, Cooper NJ, Sutton AJ, Hsu RT, Khunti K: Pharmacological and lifestyle interventions to prevent or delay type 2 diabetes in people with impaired glucose tolerance: systematic review and meta-analysis. BM] 2007, 334(7588):299.

5. Knowler WC, Barrett-Connor E, Fowler SE, Hamman RF, Lachin JM, Walker EA, Nathan DM: Reduction in the incidence of type 2 diabetes with lifestyle intervention or metformin. New England Journal of Medicine 2002, 346(6):393-403.

6. Pan XR, Li GW, Hu YH, Wang JX, Yang WY, An ZX, Hu ZX, Lin J, Xiao JZ, Cao HB, et al.: Effects of diet and exercise in preventing NIDDM in people with impaired glucose tolerance. The Da Qing IGT and Diabetes Study. Diabetes Care 1997, 20(4):537-544.

7. Ramachandran A, Snehalatha C, Mary S, Mukesh B, Bhaskar AD, Vijay $\checkmark$, for the Indian Diabetes Prevention Programme: The Indian Diabetes Prevention Programme shows that lifestyle modification and metformin prevent type 2 diabetes in Asian Indian subjects with impaired glucose tolerance (IDPP-I). Diabetologia 2006, 49(2):289-297.

8. Tuomilehto J, Lindstrom J, Eriksson JG, Valle TT, Hamalainen $H$, llanne-Parikka P, Keinanen-Kiukaanniemi S, Laakso M, Louheranta A, Rastas M, et al.: Prevention of type 2 diabetes mellitus by changes in lifestyle among subjects with impaired glucose tolerance. New England Journal of Medicine 200I, 344(18): | 343-1350.

9. Eriksson J, Lindstrom J, Valle $T$, Aunola $S$, Hamalainen $H$, llanneParikka P, Keinanen-Kiukaanniemi S, Laakso M, Lauhkonen M, Lehto $P$, et al:: Prevention of Type II diabetes in subjects with impaired glucose tolerance: the Diabetes Prevention Study (DPS) in Finland. Study design and I-year interim report on the feasibility of the lifestyle intervention programme. Diabetologia 1999, 42(7):793-80I.

10. Mensink M, Corpeleijn E, Feskens EJM, Kruijshoop M, Saris WHM, de Bruin TWA, Blaak EE: Study on lifestyle-intervention and impaired glucose tolerance Maastricht (SLIM): design and screening results. Diabetes Research \& Clinical Practice 2003, 6I(I):49-58.

II. WHO Study Group on Diabetes Mellitus: WHO Technical Report Series. Volume 727. Geneva: WHO; 1985.

12. Hays RD, Sherbourne CD, Mazel RM: The RAND 36-Item Health Survey I.0[see comment]. Health Economics 1993, 2(3):217-227.

13. Rose GABH, Gillum RF, Prineas RJ: Cardiovascular Survey Methods. In Monograph series No 56 2nd edition. Geneva: World Health Organization; 1982.

14. Nelson MAM, Meyer J: Food Portion Sizes London: MAFF; 1997.

15. Rollnick S, Mason P, Butler C: Health Behaviour Change Edinburgh: Churchill livingstone; 1999.

16. Ha TK, Lean ME: Recommendations for the nutritional management of patients with diabetes mellitus. European Journal of Clinical Nutrition 1998, 52(7):467-48I.

17. Oldroyd JC, Unwin NC, White M, Mathers JC, Alberti KGMM: Randomised controlled trial evaluating lifestyle interventions in people with impaired glucose tolerance. Diabetes Research and Clinical Practice 2006, 72: I 17-127.

18. Harland J, White M, Drinkwater C, Chinn D, Farr L, Howel D: The Newcastle exercise project: a randomised controlled trial of methods to promote physical activity in primary care. $B M J$ 1999, 3 I 9 (72 1 3):828-832. 
19. Oldroyd JC, Unwin NC, White M, Imrie K, Mathers JC, Alberti KGMM: Randomised controlled trial evaluating the effectiveness of behavioural interventions to modify cardiovascular risk factors in men and women with impaired glucose tolerance: outcomes at $\mathbf{6}$ months. Diabetes Research and Clinical Practice 200I, 52(I):29-43.

20. Penn L, Moffatt SM, White M: Participants' perspective on maintaining behaviour change: a qualitative study within the European Diabetes Prevention Study. BMC Public Health 2008, 8:235.

21. Lindstrom J, Louheranta A, Mannelin M, Rastas M, Salminen V, Eriksson J, Uusitupa M, Tuomilehto J, for the Finnish Diabetes Prevention Study Group: The Finnish Diabetes Prevention Study (DPS): Lifestyle intervention and 3-year results on diet and physical activity. Diabetes Care 2003, 26( I 2):3230-3236.

22. Lindstrom J, Tuomilehto J: The diabetes risk score: a practical tool to predict type 2 diabetes risk. Diabetes Care 2003, 26(3):725-73।.

23. Schwarz PEH, Lindstrom J, Kissimova-Scarbeck K, Szybinski Z, Barengo NC, Peltonen M, Tuomilehto J, project D-P: The European perspective of type 2 diabetes prevention: diabetes in Europe--prevention using lifestyle, physical activity and nutritional intervention (DE-PLAN) project. Experimental \& Clinical Endocrinology \& Diabetes 2008, I I 6(3): 167-172.

24. Black C: Working for a healthier tomorrow: Dame Carol Black's review of the health of Britain's working age population. Edited by health Do. London: TSO; 2008.

25. Schwarz PEH, Schwarz J, Schuppenies A, Bornstein SR, Schulze J: Development of a diabetes prevention management program for clinical practice. Public Health Reports 2007, 122(2):258-263.

26. Schwarz PEH, Gruhl U, Bornstein SR, Landgraf R, Hall M, Tuomilehto J: The European Perspective on Diabetes Prevention: Development and Implementation of A European Guideline and training standards for diabetes prevention (IMAGE). Diabetes and Vascular Disease Research 2007, 4(4):353-357.

\section{Pre-publication history}

The pre-publication history for this paper can be accessed here:

http://www.biomedcentral.com/1471-2458/9/342/pre

pub

Publish with Bio Med Central and every scientist can read your work free of charge

"BioMed Central will be the most significant development for disseminating the results of biomedical research in our lifetime. "

Sir Paul Nurse, Cancer Research UK

Your research papers will be:

- available free of charge to the entire biomedical community

- peer reviewed and published immediately upon acceptance

- cited in PubMed and archived on PubMed Central

- yours - you keep the copyright
BioMedcentral 